\title{
Superelastic Behavior of Biomedical Metallic Alloys
}

\author{
M.F. IJAZ, L. HÉRAUD, P. CASTANY, I. THIBON, and T. GLORIANT
}

In this this work, superelastic NiTi and $\mathrm{Ni}$-free Ti-23Hf-3Mo-4Sn biomedical alloys were investigated by tensile tests in relationship with their microstructures. To follow the stress-induced martensitic transformations occurring in these alloys, in situ tensile tests under synchrotron beam were conducted. In NiTi, an intermediate trigonal $\mathrm{R}$ phase, which is first stress-induced before the $\mathrm{B} 19^{\prime}$ martensitic phase, was identified. However, the Ti-23Hf-3Mo-4Sn alloy does not present a transitional phase, and a direct $\beta$ into $\alpha^{\prime \prime}$ reversible stress-induced martensitic transformation was observed. With $\mathrm{NiTi}$, all the applied strain is recovered after unloading, and no residual plastic deformation occurs. However, the strain is not completely recovered with the Ti-23Hf-3Mo-4Sn alloy, and residual plastic strain was observed to prevent a complete recovery, thus explaining why the strain recovery is lower for Ti- $23 \mathrm{Hf}-3 \mathrm{Mo}-4 \mathrm{Sn}$ compared with NiTi. We also showed that the maximum strain recovery depends on the texture in the Ti-23Hf-3Mo-4Sn alloy. The favorable texture leading to the highest strain recovery (4.6 pct) is the $\{111\}\langle 110\rangle_{\beta}$ texture, which can be obtained by a short-time solution treatment $(0.3 \mathrm{ks})$ at $1073 \mathrm{~K}$ with this alloy.

https://doi.org/10.1007/s11661-020-05840-y

(c) The Minerals, Metals \& Materials Society and ASM International 2020

\section{INTRODUCTION}

MATERIALS possessing superelastic behavior are of great interest for biomedical functional devices, and the alloys commonly used belong to the NiTi family (e.g., Nitinol) because of their exceptional shape memory and superelastic properties. Indeed, superelastic NiTi displays a very highly recoverable strain (typically 7 to 8 pct) because of the stress-induced martensitic transformation (SIM) between the B2 austenitic phase (cubic, space group $\mathrm{Pm} \overline{3} \mathrm{~m}$ ) and B19' martensitic phase (monoclinic, space group $\mathrm{P} 2_{1} / \mathrm{m}$ ). Thanks to this useful behavior, NiTi is currently used to manufacture superelastic bone staples in orthopedic, superelastic orthodontic wires and endodontic files in dentistry or self-expandable stents for cardiovascular surgery. ${ }^{[1]}$ However, there is a need to develop Ni-free alloys showing superelastic properties for biomedical

M.F. IJAZ is with the Univ Rennes, INSA Rennes, CNRS, ISCRUMR 6226, 35000 Rennes, France and also with the Mechanical Engineering Department, King Saud University, Riyadh 11421, Saudi Arabia. L. HÉRAUD is with the Univ Rennes, INSA Rennes, CNRS, ISCR - UMR 6226 and also with the Arts et Métiers-MSMP Laboratory, 13617 Aix en Provence, France. P. CASTANY, I. THIBON, and T. GLORIANT are with the Univ Rennes, INSA Rennes, CNRS, ISCR - UMR 6226. Contact e-mail: Thierry.Gloriant@insa-rennes.fr

Manuscript submitted December 11, 2019.

Article published online June 5, 2020 applications as the nickel is known to be strongly allergenic for much of the population, which remains problematic in many clinical cases. ${ }^{[2,3]}$ Consequently, highly biocompatible metastable $\beta$ titanium-based alloys containing non-cytotoxic alloying elements $(\mathrm{Nb}, \mathrm{Zr}, \mathrm{Hf}$, Mo, etc.) are now widely studied and appear to be promising candidates to replace NiTi for such biomedical devices. ${ }^{[-6]}$ The reason for this interest is because metastable $\beta$ titanium-based alloys can be mechanically unstable for certain chemical compositions. Consequently, they can also exhibit a shape memory effect and superelastic behavior. Indeed, a reversible martensitic transformation between the parent $\beta$ phase (body-centered cubic structure, space group $\operatorname{Im} \overline{3} \mathrm{~m}$ ) and the martensitic $\alpha^{\prime \prime}$ phase (C-centered orthorhombic, space group $\mathrm{Cmcm}$ ) is also observed in such alloys. ${ }^{[4-7]}$ Superelastic behavior is obtained when the quenched microstructure is composed of the -metastable phase at room temperature. In this case, the stress-induced martensitic transformation ( $\beta$ into $\left.\alpha^{\prime \prime}\right)$ can directly occur under mechanical stimulation, and large elastic recovery can be obtained because this transformation is fully reversible once the mechanical stress is released. However, a much lower elastic modulus is obtained with such superelastic alloys by comparison with the typical Ti-6Al-4V alloy currently used as prosthetic material. ${ }^{[4-7]}$ Low rigidity is known to be very beneficial to avoid the stress-shielding phenomenon, which can cause the premature loss of hip prostheses or dental implants, for example. ${ }^{[8-10]}$ Numerous works carried out on this 
kind of alloy have focused on alloys belonging to the binary $\mathrm{Ti}-\mathrm{Nb}$ system. Unfortunately, the superelastic property observed is far less than that of NiTi and does not exceed 2 pct of elastic recovery at best. ${ }^{[-6]}$ However, it was shown that addition of a third or a fourth element such as $\mathrm{Zr}$, Al or $\mathrm{Sn}$ can improve the elastic recovery. ${ }^{[11,12]}$ It is worth noting that the SIM transformation occurring in both materials remains but is still complex. In NiTi, the occurrence of a transitional phase, the $\mathrm{R}$ phase, can be occasionally observed, but the space group of this phase is still subject to controversy ${ }^{[13-15]}$ because the martensitic transformation in $\mathrm{NiTi}$ was characterized mainly under thermal cycling from shape memory $\mathrm{NiTi}^{[14]}$ and studies under stress from superelastic NiTi are few. ${ }^{[16]}$ Concerning Ni-free Ti-based alloys, the obtained recoverable strain is much lower compared with NiTi, and different strategies were employed to increase it by optimizing the chemical composition, microstructure and crystallographic texture. Consequently, significant studies have been carried out to understand which alloying elements and/or thermomechanical treatments can be tailored to ensure the optimal balance between the mechanical strength and recovery strain in superelastic $\beta$-Ti alloys. ${ }^{[17-21]}$ In most of the Ni-free superelastic titanium-based alloys, it remains difficult to find a successful combination of all the desired properties. We previously reported a new $\beta$-type Ti-23Hf-3Mo-4Sn alloy that exhibits a combination of high mechanical strength $(\sim 1 \mathrm{GPa})$, low Young's modulus (55 GPa) and large recovery strain of about 4 pct. ${ }^{[2]}$ Moreover, it was experimentally established that $1073 \mathrm{~K}$ is an appropriate temperature for the solid-solution treatment in the $\beta$-phase domain for the Ti-23Hf-3Mo-4Sn alloy. However, the influence of the solution heat treatment times on the grain size, recrystallization texture and resulting superelastic properties (such as recovery strain and critical stress inducing the martensitic transformation) has not yet been investigated. Thus, the role of the solution heat-treatment time on these microstructural and mechanical parameters was investigated in the present work. The aim of this work was also to compare the specificities of the SIM transformations occurring in NiTi and Ti-23Hf-3Mo-4Sn alloy. To achieve, in-situ tensile tests under synchrotron beam were conducted. With this method, which was recently used with success in this kind of alloy, ${ }^{[23]}$ synchrotron X-ray diffraction (SXRD) patterns were collected during strain increments to characterize the stress-induced martensitic transformation in both alloys.

\section{MATERIALS AND METHODS}

The Ti-23Hf-3Mo-4Sn (at. pct) alloy was elaborated using ultra-pure raw materials of $\mathrm{Ti}, \mathrm{Hf}$, Mo and $\mathrm{Sn}$. The synthesis of the ingot was carried out under pure argon atmosphere by the cold crucible levitation melting (CCLM) technique using a high-frequency magnetic induction generator heating system. After a homogenization step in the $\beta$-phase domain at $1223 \mathrm{~K}$ for $72 \mathrm{ks}$ under high vacuum $\left(10^{-6}\right.$ to $\left.10^{-7} \mathrm{mbar}\right)$, the obtained ingot was cold-rolled up to a reduction level $>95$ pet in thickness without intermediate annealing. The final thickness of the cold-rolled sheet was about $0.5 \mathrm{~mm}$. From the cold-rolled sheet, specimens for tensile tests were machined along the rolling direction into normalized tensile specimens $(3 \mathrm{~mm}$ width and $20 \mathrm{~mm}$ gage length). All the as-rolled specimens were solution treated in the $\beta$-phase domain at $1073 \mathrm{~K}$ under high vacuum for $0.3,0.6$ and $3.6 \mathrm{ks}$, respectively, and then quenched in water. Microstructures of the three different thermally treated states were characterized by electron-backscattering diffraction (EBSD) by using a JEOL JSM 7100F scanning electron microscope equipped with an Oxford HKL EBSD system. For the observations, specimens were mechanically "mirror" polished using a colloidal silica suspension (particle size $\sim 50 \mathrm{~nm}$ ) and then etched in a 5 pet $\mathrm{HF}, 5$ pet $\mathrm{HNO}_{3}, 90$ pet $\mathrm{H}_{2} \mathrm{O}$ (vol pet) solution. For the texture analyses, orientation distribution functions (ODFs) were calculated with the raw data of the three principal crystallographic planes $\{110\}$, $\{200\}$ and $\{211\}$ of the $\beta$ phase.

The NiTi samples were purchased from Alfa Aesar in $0.38-\mathrm{mm}$-thick sheets, with a composition of $55.8 \mathrm{pct}$ wt $\mathrm{Ni}$ and 44.2 pet wt $\mathrm{Ti}$. The normalized tensile specimens were cut by electric discharge machining from the sheets. Due to the reduced grain size, the microstructure of the NiTi alloy was observed by transmission electron microscopy (TEM) using a JEOL 2100 TEM at $200 \mathrm{kV}$. Thin foils for the TEM observations were prepared by twinjet electropolishing using a solution of 4 pet perchloric acid in methanol (vol pct) at $253 \mathrm{~K}$.

Tensile tests were carried out at room temperature on both Ti-23Hf-3Mo-4Sn and NiTi alloys to characterize their superelastic behavior (Instron ElectroPuls ${ }^{\mathrm{TM}}$ E3000). For this, cyclic loading-unloading tensile tests were conducted with a strain rate of $10^{-4} \mathrm{~s}^{-1}$. The cyclic loading/unloading tensile tests consist applied a succession of incremental tensile strains that were all followed by unloading to release the stress. For NiTi, the tensile strain was incremented by 1 up to 8 pct. In the case of the Ti-23Hf-3Mo-4Sn alloy, the tensile strain was incremented by 0.5 up to 4 pct and by 1 up to 8 pct. An extensometer was used to precisely measure the stain of each specimen.

The in-situ SXRD characterizations under stress were carried out at the European Synchrotron Radiation Facility (ESRF) in Grenoble, France, with the high-resolution beam line ID22. The incident wavelength was $0.400021 \mathrm{~nm}$, and data collection was performed in transmission at room temperature over the $2 \theta$ angular range 8 to $16 \mathrm{deg}$ with a step size of $0.005 \mathrm{deg}$. A micro-tensile test device (ADMET) was positioned in front of the beam. Under synchrotron radiation, cyclic loading/unloading tensile tests were conducted with a strain increment of 1 pet for both Ti-23Hf-3Mo-2Sn and NiTi alloys up to 8 pct. X-ray diffraction patterns were recorded for each cycle on loading and after each unloading to characterize the stress-induced martensitic transformations. Acquisition of one diffractogram takes 5 minutes. The geometry of the setup consists of an incident X-ray beam arriving perpendicularly to the 
surface of the tensile specimen (and thus to the tensile direction), and the transmitted diffracted beams are then collected with a nine-channel multi-analyzer 1D detector (see a sketch of the setup in Reference 16). Due to this geometry, only crystallographic planes roughly parallel to the incident beam, i.e., perpendicular to the tensile direction, are in diffracting condition and then collected by the detector. As shown further, the investigated alloys possess a strong crystallographic texture in their initial state leading to mainly one unique diffracted peak corresponding to the $\{110\}$ planes perpendicular to the tensile direction for both Ti-23Hf-3Mo-2Sn and NiTi alloys. Consequently, diffracted beams of almost all grains are collected, resulting in a representative analysis of the specimens.

\section{RESULTS AND DISCUSSION}

\section{A. Microstructures}

Figure 1 displays a typical bright-field TEM image showing the microstructure of the NiTi alloy. The corresponding electron diffraction pattern, also presented in this figure, is indexed as a $\langle 110\rangle$ zone axis of the B2 phase. As can be seen, this alloy presents a very refined equiaxed B2-grains microstructure with a grain size of about $100 \mathrm{~nm}$.

Typical EBSD inverse pole figure (IPF) maps obtained from the Ti-23Hf-3Mo-4Sn alloy subjected to the three different solution treatment times $(0.3,0.6$ and $3.6 \mathrm{ks}$ ) at $1073 \mathrm{~K}$ are shown in Figures 2(a) through (c), respectively. The color code corresponding to the crystallographic grain orientations is shown in Figure 2(d) (the rolling direction is represented).

All the samples show a typical equiaxed $\beta$-grain microstructure. The grain size is larger when the duration of the treatment is longer. Typically, the maximum grain size is a few hundred microns when the alloy is treated for $3.6 \mathrm{ks}$, while it is a few tens of microns when the alloy is treated for $0.3 \mathrm{ks}$. On the other hand, a change of texture is clearly observed between the

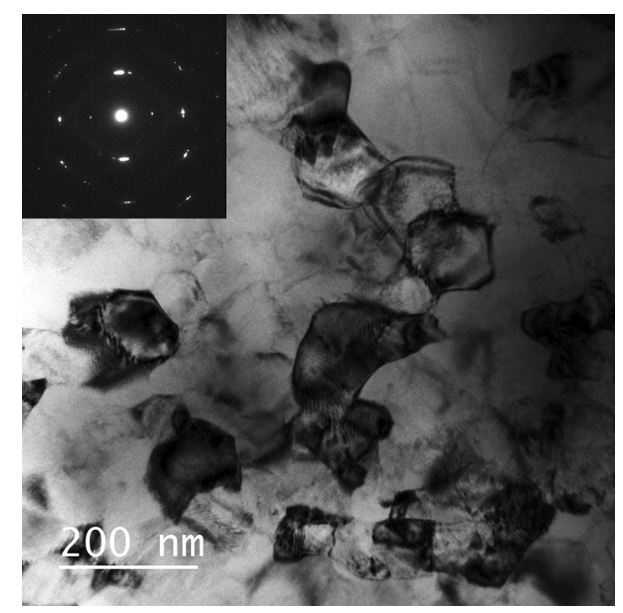

Fig. 1-Bright-field TEM image and the corresponding electron diffraction pattern of the NiTi alloy. short time treatment and the longer one. These observations are not surprising since it is well known that the recrystallization conditions greatly influence the grain size and the texture in many metallic alloys. ${ }^{[24]}$

To discuss the effect of the different solution treatment times on the development of the recrystallization texture in $\mathrm{Ti}-23 \mathrm{Hf}-3 \mathrm{Mo}-4 \mathrm{Sn}$, the orientation distribution function (ODF) was obtained from the EBSD data. Figures 3(a) through (c) shows the different $\phi=45 \mathrm{deg}$ ODF sections obtained after each solution treatment (at $1073 \mathrm{~K}$ for $0.3,0.6$ and $3.6 \mathrm{ks}$, respectively).

When the alloy is treated at $1073 \mathrm{~K}$ for $0.3 \mathrm{ks}$ (Figure 3(a)), the major component of the recrystallization texture is concentrated around the $\{111\}\langle 110\rangle_{\beta}$ orientation and also along the $\alpha$-fiber $\{h \mathrm{kl}\}\langle 110\rangle_{\beta}$, that is for $\varphi_{1}=0$ and $\varphi_{2}=45 \mathrm{deg}$. For a solution treatment at $1073 \mathrm{~K}$ for $0.6 \mathrm{ks}$ (Figure 3(b)), the specimen shows a recrystallization texture with a major $\{113\}\langle 471\rangle_{\beta}$ component. A weaker $\gamma$-fiber, containing all the orientations of $\{111\}\langle\mathrm{uvw}\rangle_{\beta}$, was also identified on the ODF section. Additionally, a very weak intensity was also observed for the $\{001\}_{\beta}\langle 110\rangle_{\beta}$ component $(\varphi 1=90$ $\operatorname{deg}$ and $\varphi=0)$ as well as a weak $\alpha$-fiber $\left(\{\mathrm{hkl}\}\langle 110\rangle_{\beta}\right.$ (along $\varphi 1=0)$. For a longer solution treatment time $(3.6 \mathrm{ks})$, the maximum intensities are visible for the $\{111\}\langle 112\rangle_{\beta}$ texture component (Figure 3(c)). Therefore, a clear texture transition is shown for this alloy composition at $1073 \mathrm{~K}$ as the function of the solution treatment time, from $\{111\}\langle 110\rangle_{\beta}$ texture (short time treatment) to $\{111\}\langle 112\rangle_{\beta}$ texture (longer time treatment).

\section{B. Tensile Tests}

To characterize the superelastic properties of both Ti-23Hf-3Mo-4Sn and NiTi alloys, cyclic tensile tests were carried out. Figures 4(a) through (c) shows the loading-unloading stress-strain curves from the Ti-23Hf-3Mo-4Sn solution treated at $1073 \mathrm{~K}$ for 0.3 , 0.6 and $3.6 \mathrm{ks}$, respectively, while Figure 4(d) displays the cyclic tensile curve from the NiTi alloy.

As these curves show, both Ti-23Hf-3Mo-4Sn and NiTi alloys present a stress plateau associated with the stress-induced martensitic transformation (SIM) occurring in these superelastic materials. The critical stress inducing the martensitic transformation, $\sigma_{\mathrm{c}}$, which corresponds to the beginning of the stress plateau, is about 400-450 $\mathrm{MPa}$ for the Ti-23Hf-3Mo-4Sn alloy (Figures 4(a) through (c)) and about $370 \mathrm{MPa}$ for NiTi (Figure 4(d)). The loops observed between loading and unloading indicate the reversibility of the transformation (reverse martensitic transformation) in accordance with the thermoelastic nature of such displacive transformations. Their superelastic behavior is however different. For NiTi, the stress plateau, lying from about 2 pct to about 6 pct of strain, is perfectly flat and the stress remains constant at about $370 \mathrm{MPa}$ during the martensitic transformation. However, all the applied strain is recovered and no residual plastic deformation occurs after unloading, whatever the applied strain. Contrarily, in the Ti-23Hf-3Mo-4Sn alloy, the stress plateau, lying from about 1 pet to about 4 pet of strain, 

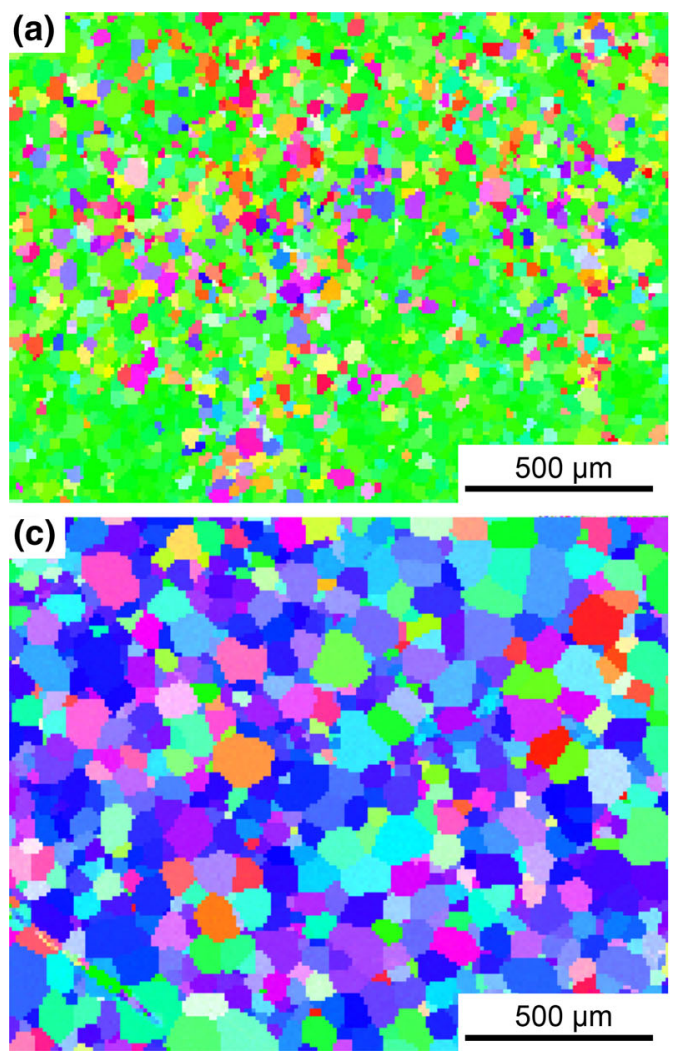

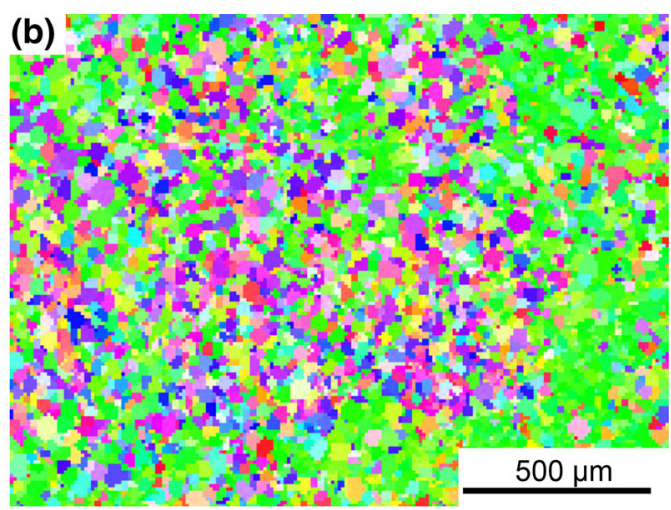

(d)

$\mathrm{RD}$

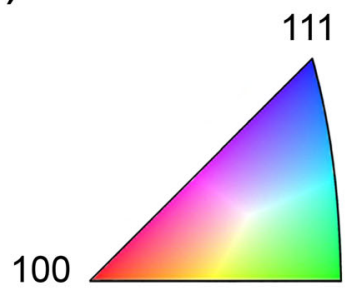

110

Fig. 2-EBSD RD (rolling direction) IPF maps of solution-treated Ti-23Hf-3Mo-4Sn alloy samples at $1073 \mathrm{~K}$ for $0.3 \mathrm{ks}(a)$, $0.6 \mathrm{ks}(b)$ and 3.6 ks $(c)$ with the corresponding IPF color code $(d)$ (Color figure online).

is not flat, and an increase of the stress is seen after each increment. With the Ti-23Hf-3Mo-4Sn alloy, the applied strain is not completely recovered and residual plastic strain can be observed, which increases with the imposed strain. This means that the thermoelastic nature of the martensitic transformation in the Ti-23Hf-3Mo-4Sn alloy is not "perfect" and dislocations are generated during the SIM transformation. The continuous increase of the tensile stress can thus be associated with a strain-hardening effect induced by the plasticity. Consequently, the mobility of the martensitic variants is upset by these created dislocations, and a complete strain recovery cannot be obtained, contrary to what is happening with NiTi. This residual plasticity thus prevents a complete recovery on unloading, which is why the strain recovery is lower for $\beta$-type Ti-based alloys compared with NiTi.

To quantify the superelastic characteristics of the Ti-23Hf-3Mo-4Sn alloy, the total recovery strain, $\varepsilon_{r}$, and the residual plastic strain, $\varepsilon_{p}$, were measured for each loading-unloading cycle for the three solution treatments. An example of such measurements on one loading-unloading loop is illustrated on the cyclic tensile curve in Figure 4(a). Figure 5 presents the evolutions of $\varepsilon_{r}$ and $\varepsilon_{p}$ as the function imposed strain during the cyclic tensile tests for the three solution treatments: $0.3 \mathrm{ks}$ (a), $0.6 \mathrm{ks}$ (b) and $3.6 \mathrm{ks}$ (c). In these figures, the maximum recovery strains, $\varepsilon_{r}^{\max }$, were highlighted for each condition (dashed slines). As the graphs show, all the specimens display a similar tendency as a function of the imposed strain: the residual plastic strain, $\varepsilon_{p}$, increases continuously, and the strain recovery, $\varepsilon_{r}$, increases up to the maximum value, $\varepsilon_{r}^{\max }$, and then decreases. This decrease is due to the multiplication of dislocations, which prevents the reverse martensitic transformation. Therefore, the fact that plasticity occurs in the Ti-23Hf-3Mo-4Sn alloy during the martensitic transformation represents a noticeable difference to what is happening with the NiTi. Indeed, no plasticity occurs for the latter, which results in a constant stress during the martensitic transformation, thus leading to a higher recoverable deformation. In the Ti-23Hf-3Mo-4Sn alloy, we notice a difference between the maximum recovery strain values, $\varepsilon_{r}^{\max }$, which depend of the treatment time and are measured to be around 4.6, 3.9 and 3.6 pet for $0.3,0.6$ and $3.6 \mathrm{ks}$, respectively. The highest maximum recovery strain $(4.6 \mathrm{pct})$ is obtained when the alloy is solution treated with the shortest time $(0.3 \mathrm{ks})$. This result can be directly linked with the crystallographic texture. Indeed, it has been previously reported that the transformation strain is due to the lattice transformation strain capacity between $\beta$ and $\alpha^{\prime \prime}$ phases in this kind of alloys, ${ }^{[25]}$ and grains with $\langle 110\rangle$ directions parallel to the tensile direction were shown to exhibit the larger recovery strain. ${ }^{[26,27]}$ We showed in the present study that only the alloy treated for $0.3 \mathrm{ks}$ has this clear favorable texture. 

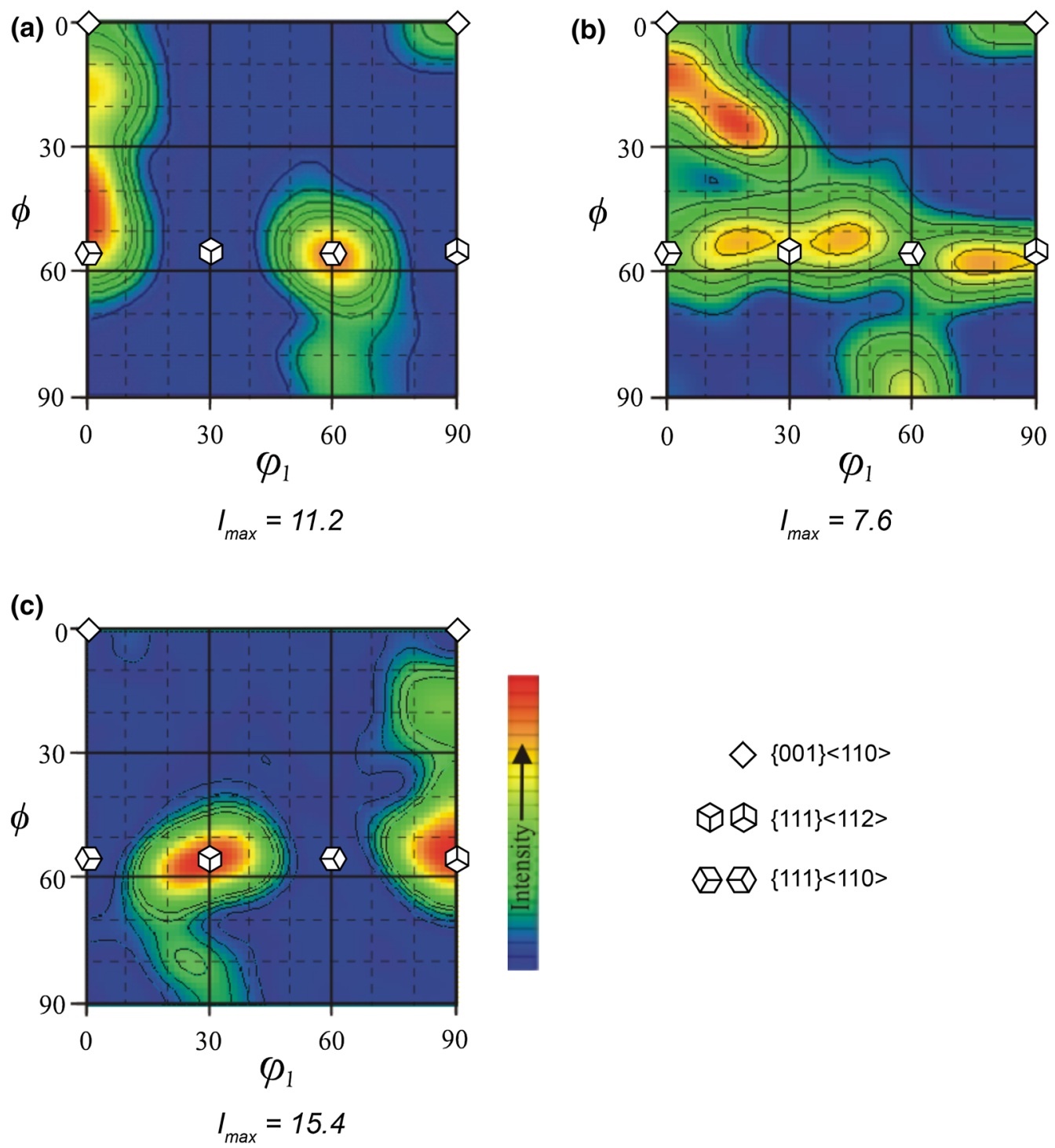

Fig. 3 - Sections $\left(\phi_{2}=45 \mathrm{deg}\right)$ of the orientation distribution function for the Ti-23Hf-3Mo-4Sn alloy specimens solution treated at $1073 \mathrm{~K}$ for $0.3 \mathrm{ks}(a), 0.6 \mathrm{ks}(b)$ and $3.6 \mathrm{ks}(c)$.

\section{SXRD Analyses}

The SXRD patterns collected under loading at different maintained strain and after each unloading are presented in Figure 6 for NiTi and in Figure 7 for the Ti-23Hf-3Mo-4Sn alloy solution treated at $1073 \mathrm{~K}$ for $0.3 \mathrm{ks}$.

The B2 austenitic phase is clearly identified from NiTi in its initial state, and all the B2 diffracted peaks are well indexed in the SRXD pattern $(0$ pct $)$. Patterns under loading (Figure 6(a)) show that the B2 austenite peak intensities are decreasing when the strain rises and additional peaks appear. These additional peaks, appearing from 1 pet strain, do not correspond to B19' martensitic phase but are very well indexed with the trigonal $\mathrm{R}$ phase (space group $\mathrm{P} \overline{3}$ ) already reported in the literature. ${ }^{[15]}$ Moreover, the occurrence of this transitional phase between $\mathrm{B} 2$ and $\mathrm{B} 19^{\prime}$ is consistent with the tensile curve, where a change in slope can be observed in the elastic deformation portion of the tensile curve in Figure 4(d). ${ }^{[16]}$ The relative intensity of the R-phase peaks increases until that the B19' martensite's more intense peak, $(110)_{\mathrm{B} 19^{\prime}}$, starts to appear at 2 pct strain, which corresponds to the beginning of the plateau on the tensile curve. Notably, the R phase coexists with both martensitic B19' and austenitic B2 phases up to 4 pct strain before completely disappearing. From about 6 pct of deformation, the NiTi is mainly martensitic. Along the plateau, the martensite peaks are growing while the austenite peaks are decreasing until disappearing. It can be observed that all the SXRD patterns obtained after each unloading (Figure 6(b)) only display the peaks related to the B2 austenitic phase. This means that the stress-induced $\mathrm{R}$ phase is also reversible as well as the $\mathrm{B} 19^{\prime}$ phase. Concerning the Ti-23Hf-3Mo-4Sn alloy (Figure 7), the intense $(110)_{\beta}$ peak confirms that this alloy is fully $\beta$ at the initial state. Under loading (Figure 7(a)), the $\alpha^{\prime \prime}$ SIM transformation is observed without the presence of an 

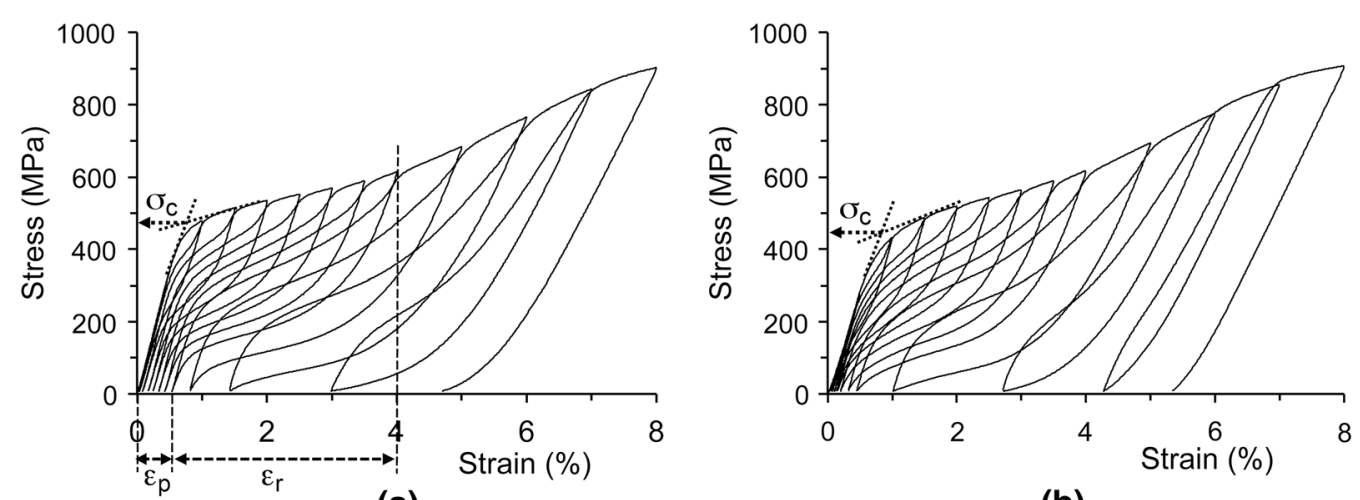

(a)

(b)
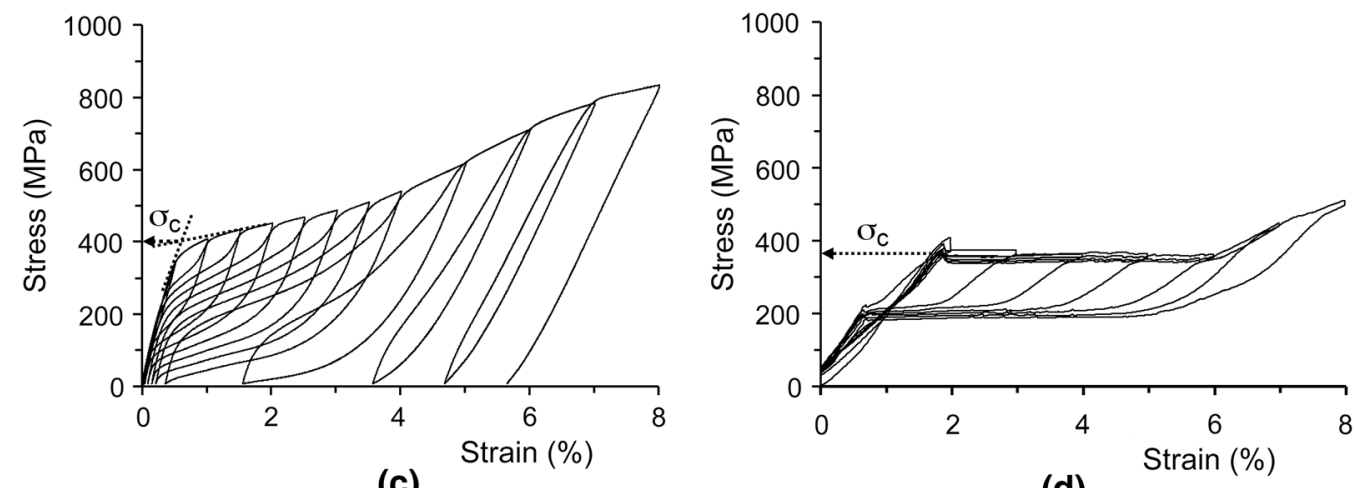

Fig. 4 Cyclic tensile curves obtained from solution-treated Ti-23Hf-3Mo-4Sn alloy samples at $1073 \mathrm{~K}$ for $0.3 \mathrm{ks}(a)$, 0.6 ks $(b)$ and 3.6 ks $(c)$, respectively, and from the NiTi alloy $(d)$.

intermediate phase. This transformation is highlighted by the fact that the intensity of the $(110)_{\beta}$ peak is decreasing gradually upon deformation while the $(020)_{\alpha^{\prime \prime}}$ peak is appearing first, followed by the other $\alpha^{\prime \prime}$ peaks. For both alloys the reversibility of the SIM transformation is shown by the relative increase of the austenitic peak after unloading with respect to the corresponding loading level. Thus, SXRD confirms that complete reversibility is still obtained at up to 8 pct of strain for $\mathrm{NiTi}$ and only $<4$ pet for Ti-23Hf-3Mo-4Sn, in good accordance with the cyclic tensile curves.

\section{FUTURE PERSPECTIVES}

Even if the Ni-free titanium alloys have an interesting superelasticity, the recoverable strains are nevertheless still lower than those obtained with alloys of the NiTi family. As we have seen with the Ti-23Hf-3Mo-4Sn alloy, the applied strain is not completely recovered and residual plastic strain is observed, which is not the case with NiTi. This plasticity therefore originates from the formation of dislocations that are generated by the SIM transformation in this alloy. Therefore, observations of dislocation generation and mobility induced by the $\alpha^{\prime \prime}$ martensitic transformation would be of great interest in understanding the plasticity mechanism that occurs. This can be investigated by in situ straining experiments in a transmission electron microscope (TEM). In a previous study carried out by in situ straining, ${ }^{[28]}$ dislocations with $a / 2\langle 111\rangle$ Burgers vectors were observed to glide in $\left\{\begin{array}{lll}1 & 1 & 0\end{array}\right\},\left\{\begin{array}{lll}1 & 1 & 2\end{array}\right\}$ or $\left\{\begin{array}{lll}1 & 2 & 3\end{array}\right\}$ planes in a metastable $\beta$ titanium alloy. It was particularly observed that the deformation is carried by long screw segments because of their lower mobility than non-screw segments. Although interesting, these observations were however carried out on alloys that do not exhibit stress-induced martensitic transformation. Although a similar investigation was also attempted on the Ti-23Hf-3Mo-4Sn alloy of the present study, it was not possible to highlight the role of $\alpha^{\prime \prime}$ phase on the dislocation behavior. Indeed, this $\alpha^{\prime \prime}$ phase does not seem to want to form under stress in TEM samples because of their very reduced thicknesses, which generate mechanical relaxations. The solution would be to study more stable alloys, which may be possible by adding interstitial elements in the chemical composition ( $\mathrm{N}$ or $\mathrm{O}$ ), which have shown a stabilizing effect for the $\alpha^{\prime \prime}$ phase formed under stress. ${ }^{[29]}$ To increase the recoverable strain in metastable $\beta$ titanium alloys, one solution could be to reduce the $\beta$-grain size. Indeed, a previous study showed that the superelastic property of these alloys could be improved when the grain size decreases. ${ }^{[30]}$ A refined microstructure should increase the critical stress for slip by the Hall-Petch effect to minimize the harmful role of plasticity. To do this, severe plastic deformation techniques (SPD) could be envisaged, which have never been carried out on this type of alloy to our knowledge. Another possibility would be to study the fatigue properties of superelastic 


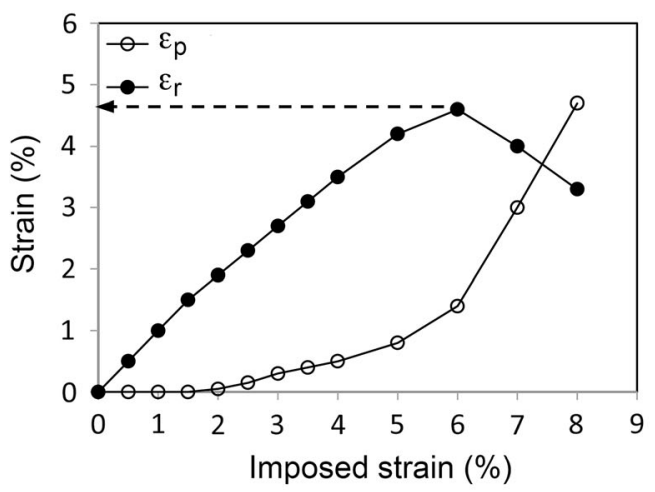

(a)

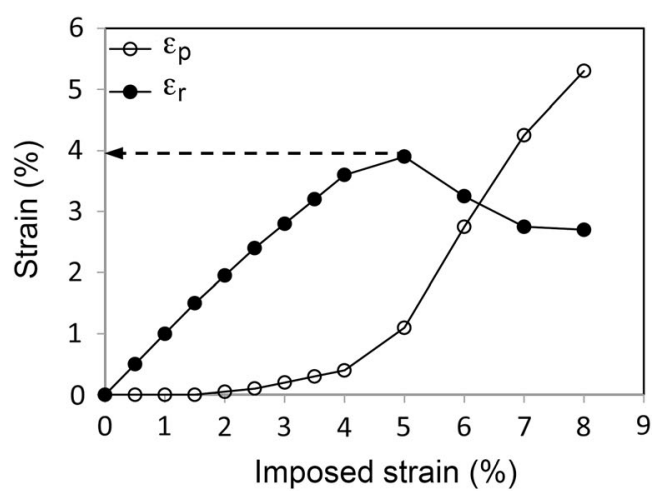

(b)

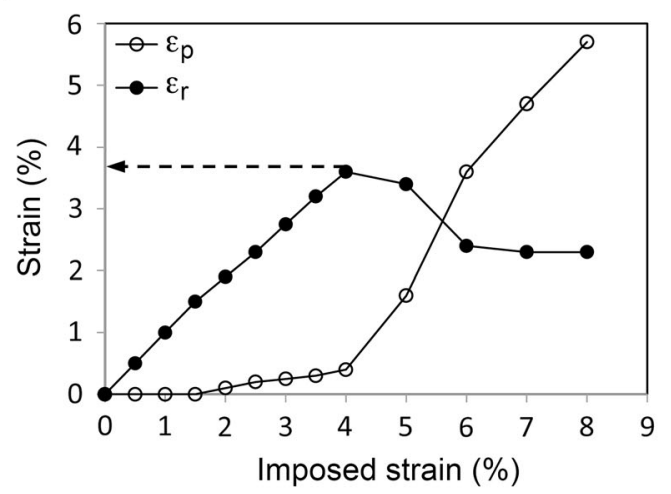

(c)

Fig. 5-Evolutions of the superelastic recovery strain, $\varepsilon_{r}$, and the residual plastic strain, $\varepsilon_{p}$ as the function of the imposed strain during loading-unloading cycles for the Ti-23Hf-3Mo-Sn alloy specimens solution treated at $1073 \mathrm{~K}$ for $0.3 \mathrm{ks}(a)$, $0.6 \mathrm{ks}(b)$ and $3.6 \mathrm{ks}(c)$.

Ni-free titanium-based alloys. Indeed, certain biomedical devices such as vascular stents or endodontic files are subjected to cyclic mechanical strain in service (heartbeat for stents, rotation cycles for files), and few studies exist on superelastic Ni-free alloys. The study of the fatigue behavior of biomedical metastable $\beta$ titanium alloys is more recent than that of NiTi and was mainly carried out on Ti-Nb-Zr and Ti-Nb-Ta-Zr alloys. ${ }^{[8,31,32]}$ These alloys have demonstrated fatigue life characteristics comparable to those of commercial biomedical grades (Ti-6Al-4V ELI and Ti-6Al-7Nb) under uniaxial solicitation. Some studies also exist in rotary bending ${ }^{[33]}$ and conclude that $\beta$ metastable titanium alloys have fatigue properties comparable to those of NiTi. However, further fatigue studies are still necessary to consider the use of this type of alloy for the manufacture of medical devices. Finally, it is clear that a detailed assessment of the biocompatibility must be carried out to validate a new alloy as an implantable biomaterial. For this, studies of resistance to biocorrosion in simulated body fluids and cytocompatibility tests in cell cultures can be quickly done for a first validation before considering in vivo studies on animal models.

\section{CONCLUSION}

In this study, two classes of superelastic alloys, i.e., a NiTi (55.8 pet wt of $\mathrm{Ni}$ and 44.2 pet wt of $\mathrm{Ti}$ ) and a
Ni-free Ti-23Hf-3Mo-4Sn alloy composition (at. pct), were compared. In their initial states, both alloys are austenitic: B2 phase for NiTi and $\beta$ phase for Ti-23Hf-3Mo-4Sn. The stress-induced martensitic transformations (SIM) occurring in both alloys were characterized by cyclic tensile tests to compare their mechanical behavior. With NiTi, all the applied strain is recovered after unloading and no residual plastic deformation occurs. On the contrary, the strain is not completely recovered with the Ti-23Hf-3Mo-4Sn alloy and residual plastic strain was observed to prevent a complete recovery, thus explaining why the strain recovery is lower for the $\beta$-type Ti-based alloys (around 4 pct) compared with $\mathrm{NiTi}$ (around $8 \mathrm{pct}$ ). We also showed that the maximum strain recovery depends on the texture in the Ti-23Hf-3Mo-4Sn alloy. The favorable texture leading to the highest strain recovery (4.6 pct) is the $\{111\}\langle 110\rangle_{\beta}$ texture, which can be obtained by a short-time solution treatment $(0.3 \mathrm{ks})$ at $1073 \mathrm{~K}$ with this alloy. However, we showed that SIM transformations can be clearly characterized by in situ SXRD analyses in both alloys. In NiTi, we have identified the intermediate trigonal $\mathrm{R}$ phase (space group $\mathrm{P} \overline{3}$ ), which is first stress-induced before the B19' martensitic phase. It was observed that the martensitic $R$ phase is also reversible after unloading as in the case of the martensitic B19' phase. On the contrary, the Ti-23Hf-3Mo-4Sn alloy does not present a transitional phase, and a direct $\beta$ into $\alpha^{\prime \prime}$ reversible stress-induced martensitic 

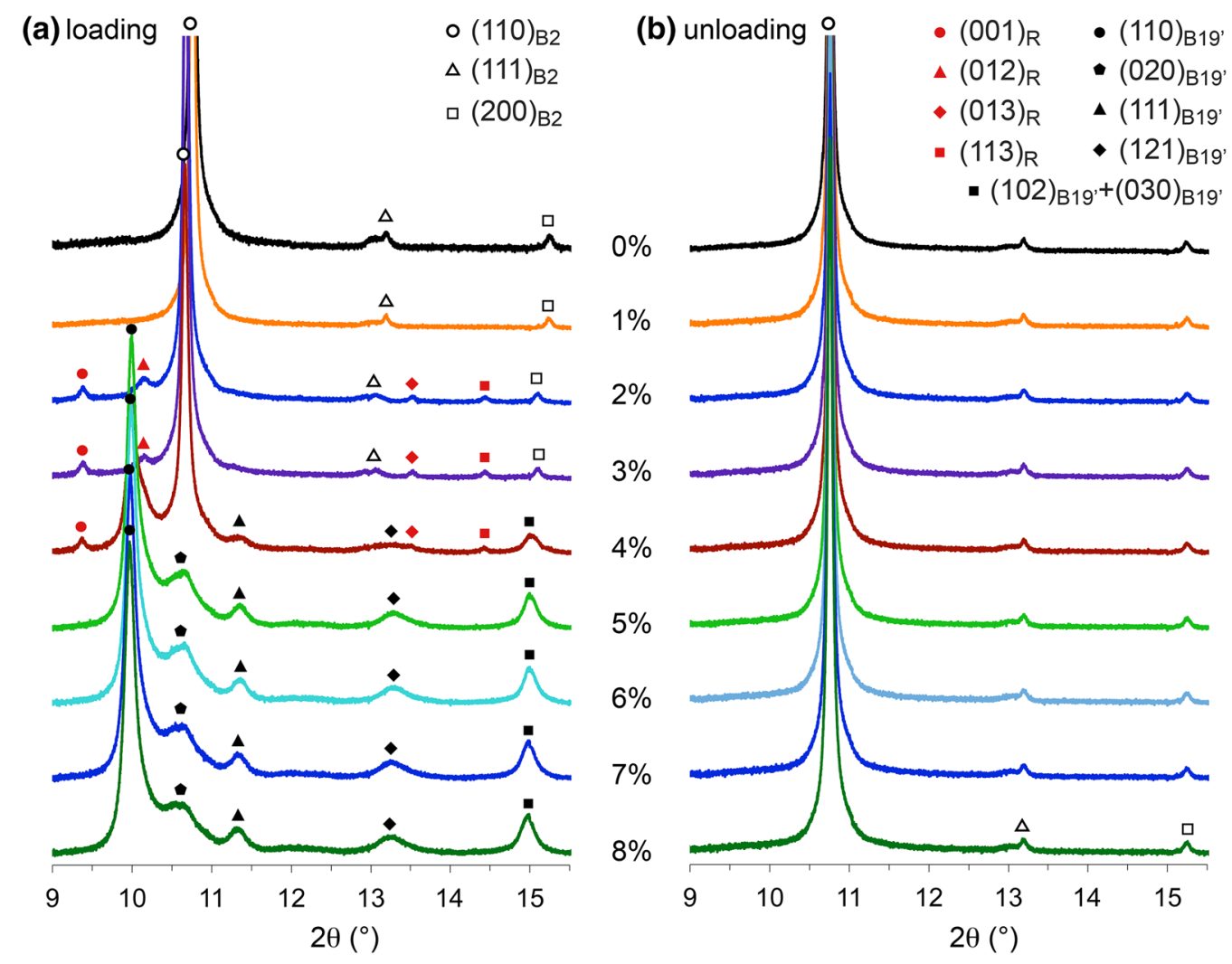

Fig. 6-SXRD patterns corresponding to the different incremental strain pet under loading (a) and after each unloading (b) for NiTi.
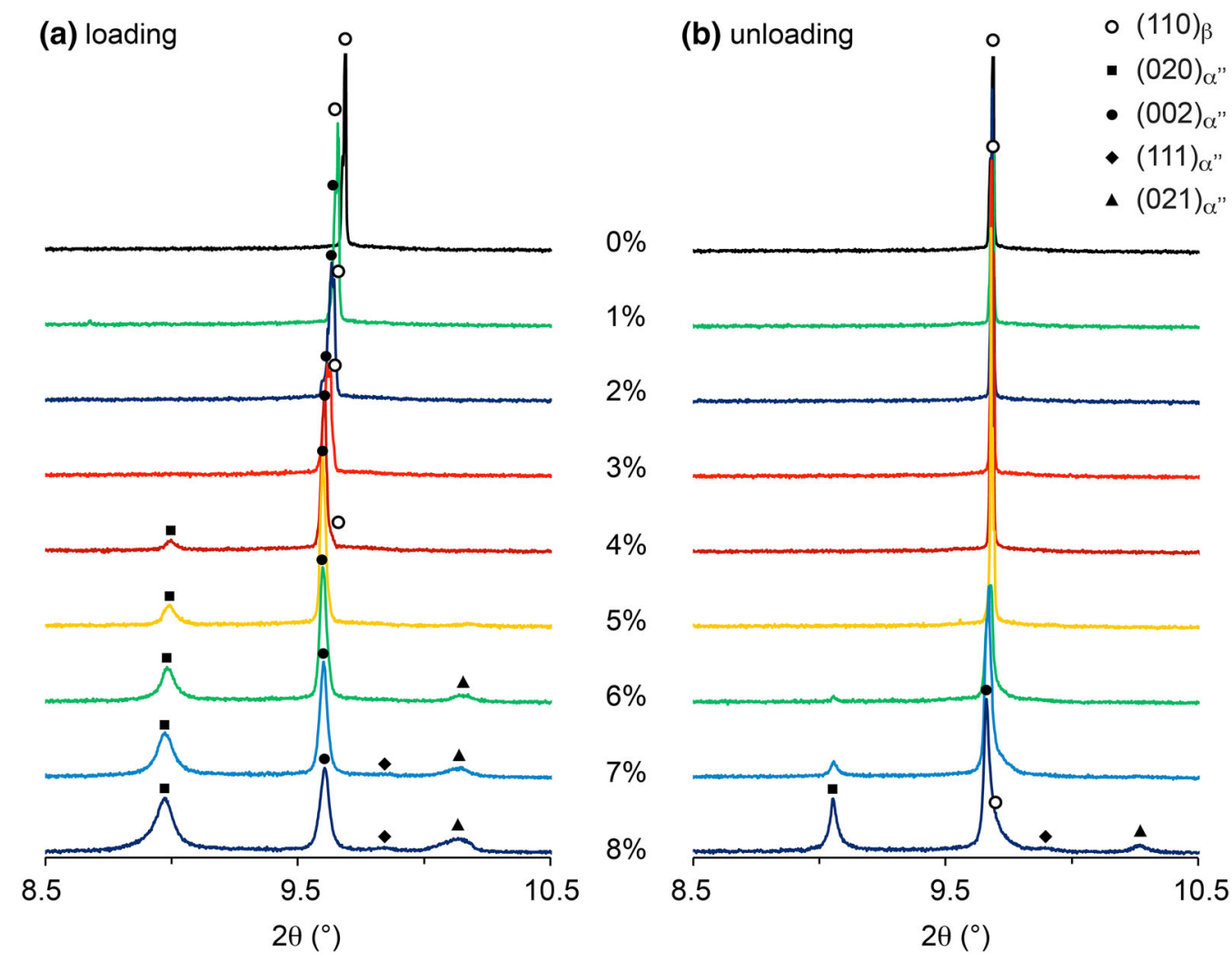

Fig. 7-SXRD patterns corresponding to the different incremental strain pct under loading $(a)$ and after each unloading (b) for Ti-23Hf-3Mo-4Sn. 
transformation was observed. Even if the Ni-free Ti-23Hf-3Mo-4Sn alloy has an interesting superelasticity, the recoverable strains are nevertheless still lower than those obtained with alloys of the NiTi family, and further investigation must be carried out to consider the use of this type of Ni-free alloy for the manufacture of medical devices.

\section{ACKNOWLEDGMENTS}

This study was financially supported by the French ANR (Project BIOMIMETIS ANR-13-IS09-0008-01). The authors acknowledge the European Synchrotron Radiation Facility for provision of the synchrotron radiation facilities of the beamline ID22. The authors also acknowledge the THEMIS and CMEBA platforms of the University of Rennes for providing access to the TEM and SEM-EBSD facilities, respectively.

\section{REFERENCES}

1. T. Duerig, A. Pelton, and D. Stockel: Mater. Sci. Eng. A, 1999, vols. 273-275, pp. $149-60$.

2. S.A. Shabalovskaya: Bio-Med. Mater. Eng., 2002, vol. 12, pp. 69-109.

3. D.J. Wever, A.G. Veldhuizen, M.M. Sanders, J.M. Schakenraad, and J.R. Van Horn: Biomaterials, 1997, vol. 18, pp. 1115-20.

4. H.Y. Kim, Y. Ikehara, J.I. Kim, H. Hosoda, and S. Miyazaki: Acta Mater., 2006, vol. 54, pp. 2419-29.

5. P. Castany, D.M. Gordin, S.I. Drob, C. Vasilescu, V. Mitran, A. Cimpean, and T. Gloriant: Shap. Mem. Superelasticity, 2016, vol. 2, pp. 18-28.

6. S. Miyazaki, H.Y. Kim, and H. Hosoda: Mater. Sci. Eng. A, 2006 , vols. 438-440, pp. 18-24.

7. E. Bertrand, P. Castany, and T. Gloriant: Acta Mater., 2013, vol. 61, pp. 511-18.

8. M. Niinomi: Biomaterials, 2003, vol. 24, pp. 2673-83.

9. P. Laheurte, F. Prima, A. Eberhardt, T. Gloriant, M. Wary, and E. Patoor: J. Mech. Behav. Biomed. Mater., 2010, vol. 3, pp. $565-73$.

10. R. Huiskes, H. Weinans, and B. Van Rietbergen: Clin. Orthop. Rel. Res., 1992, vol. 274, pp. 124-34.
11. Y. Fukui, T. Inamura, H. Hosoda, K. Wakashima, and S. Miyazaki: Mater. Trans., 2004, vol. 45, pp. 1077-82.

12. Y.L. Hao, Z.B. Zhang, S.J. Li, and R. Yang: Acta Mater., 2012, vol. 60 , pp. $2169-77$.

13. K. Otsuka and X. Ren: Prog. Mater. Sci., 2005, vol. 50, pp. $511-78$.

14. T. Goryczka and H. Morawiec: J. All. Compd., 2004, vol. 367, pp. $137-41$.

15. J. Khalil-Allafi, W.W. Schmahl, and D.M. Toebbens: Acta Mater., 2006, vol. 54, pp. 3171-75.

16. M.L. Young, M.F.-X. Wagner, J. Frenzel, W.W. Schmahl, and G. Eggeler: Acta Mater., 2010, vol. 58, pp. 2344-54.

17. H. Hosoda, Y. Kinoshita, Y. Fukui, T. Inamura, K. Wakashima, H.Y. Kim, and S. Miyazaki: Mater. Sci. Eng. A, 2006, vol. 438, pp. $870-74$.

18. M. Tahara, H.Y. Kim, H. Hosoda, T. Nam, and S. Miyazaki: Mater. Sci. Eng. A, 2010, vol. 527, pp. 6844-52.

19. F. Sun, Y.L. Hao, S. Nowak, T. Gloriant, P. Laheurte, and F. Prima: J. Mech. Behav. Biomed. Mater., 2011, vol. 4, pp. 1864-72.

20. M.F. Ijaz, H.Y. Kim, H. Hosoda, and S. Miyazaki: Mater. Sci. Eng. C, 2015, vol. 48, pp. 11-20.

21. L.L. Pavón, H.Y. Kim, H. Hosoda, and S. Miyazaki: Scripta Mater., 2015, vol. 95, pp. 46-49.

22. M.F. Ijaz, D. Laillé, L. Héraud, D.-M. Gordin, P. Castany, and T. Gloriant: Mater. Lett., 2016, vol. 177, pp. 39-41

23. P. Castany, A. Ramarolahy, F. Prima, P. Laheurte, C. Curfs, and T. Gloriant: Acta Mater., 2015, vol. 88, pp. 102-11.

24. R.D. Doherty: Prog. Mater. Sci., 1997, vol. 42, pp. 39-58.

25. M. Tahara, H.Y. Kim, T. Inamura, H. Hosoda, and S. Miyazaki: Acta Mater., 2011, vol. 59, pp. 6208-18.

26. T. Inamura, Y. Fukui, H. Hosoda, K. Wakashima, and S. Miyazaki: Mater. Trans., 2004, vol. 45, pp. 1083-89.

27. J.J. Gao, I. Thibon, D. Laillé, P. Castany, and T. Gloriant: Mater. Sci. Eng. A, 2019, vol. 762, p. 138075.

28. P. Castany, M. Besse, and T. Gloriant: Scripta Mater., 2012, vol. 66, pp. 371-73

29. A. Ramarolahy, P. Castany, F. Prima, P. Laheurte, I. Péron, and T. Gloriant: J. Mech. Behav. Biomed. Mater., 2012, vol. 9, pp. 83-90.

30. F. Sun, S. Nowak, T. Gloriant, P. Laheurte, A. Eberhardt, and F. Prima: Scripta Mater., 2010, vol. 63, pp. 1053-56.

31. V. Sheremetyev, V. Brailovski, S. Prokoshkin, K. Inaekyan, and S. Dubinskiy: Mater. Sci. Eng. C, 2016, vol. 58, pp. 935-44.

32. M. Niinomi: Int. J. Fatigue, 2007, vol. 29, pp. 992-1000.

33. J. Guillem-Martí, C. Herranz-Díez, J.E. Shaffer, F.J. Gil, and J.M. Manero: Mater. Sci. Eng. A, 2015, vol. 636, pp. 507-15.

Publisher's Note Springer Nature remains neutral with regard to jurisdictional claims in published maps and institutional affiliations. 